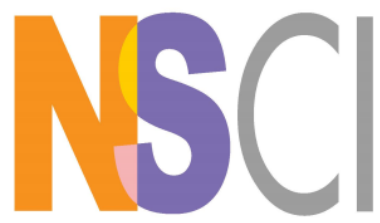

Current Perspectives on Medicinal and Aromatic Plants

An International Journal

ISSN: 2619-9645 | e-ISSN: 2667-5722

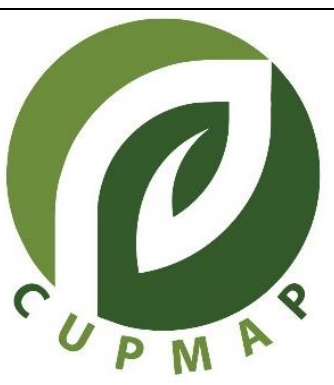

\title{
Plant-Based Milk Alternative: Nutritional Profiling, Physical Characterization and Sensorial Assessment
}

\author{
Mariem Ben JEMAA* (D) \\ $\underline{\text { Riadh KSOURI }}$ Raja Serairi BEJI $^{\text {Rad }}$ \\ ${ }^{1}$ Laboratory of Aromatic and Medicinal Plants, Biotechnology center of Borj-Cédria, \\ BP 901, 2050 Hammam-lif, Tunisie \\ 2Université Mahmoud El Materi, 10, rue Bourgine, Montplaisir, Tunis, Tunisie \\ 3École Supérieure des Sciences et Techniques de la Santé de Tunis. Tunisie \\ *Corresponding author: mariembenjemaa@hyahoo.fr
}

\begin{abstract}
The aim of this work was the characterization of four plant-based milks: oat, almond, hemp, and quinoa's milk. The nutritional composition of each milk, as well as its physico-chemical characteristics, microbiologic stability, and antioxidant potential, were determined in order to investigate the effect of the first ingredient on the overall quality of the plant-based milk. Finally, a hedonic sensory analysis was conducted in order to determine the acceptability of these products. In terms of nutritional value, obtained results highlighted that oat's milk has the highest carbohydrate, protein and fiber contents $(23 \mathrm{~g} / 100 \mathrm{ml}, 5 \mathrm{~g} / 100 \mathrm{ml}$ and $3 \mathrm{~g} / 100 \mathrm{ml}$, respectively). However, hemp's milk has the highest fat and calcium content $(7 \mathrm{~g} / 100 \mathrm{ml}$ and 37.5 $\mathrm{mg} / 100 \mathrm{ml}$, respectively). The $\mathrm{pH}$ of tested plant-based milk, were all similar and close to neutrality. The Withening Index (WI) values found were 21.46 for almond's milk, 9.48 for oat's milk, 34.97 for hemp's milk, and 0.1 for quinoa's milk. The antioxidant capacity assessment demonstrated that tested plant-based milk have an interesting potential. Measured inhibition capacities ranged from $78.34 \%$ (quinoa's milk) to 63.14 $\%$ (oat's milk), and their total polyphenol content ranged from $0.310 \mathrm{mg}$ EAG/g DM (oat's milk) to $0.836 \mathrm{mg}$ EAG/g DM (quinoa's milk). The microbial stability results showed that quinoa's milk had the best bacterial stability, with a maximum denomination of $56 * 104 \mathrm{UFC} / \mathrm{ml}$ for the first 8 days of storage, while almond and oat's milks had better fungal stability and were free of contaminants up to the eighth day of storage. During the hedonic sensory analysis, the almond's milk was the most appreciated by the panelist. Gathered results suggest that plant-based milks are high in nutrients and phenolic compounds, and they deserve to be considered as "healthy aliment".
\end{abstract}

Key Words: Plant-based milks; Nutritional composition; Microbiologic stability; Sensory analysis

(c) CUPMAP. All rights reserved.

\section{Introduction}

Milk and dairy products are ranked fourth on the food pyramid, and it is undoubtedly their nutritional value that has earned them a place among the essential foods for human health. Apart from its high content of macronutrients such as proteins
$(3.25 \mathrm{~g} / 100 \mathrm{~g})$, carbohydrates $(4.85 \mathrm{~g} / 100 \mathrm{~g})$, and lipids $(3.63 \mathrm{~g} / 100 \mathrm{~g})$, as well as micronutrients such as vitamins (vitamin A, $B$, and D) and minerals (calcium, phosphorus), milk is a multi-beneficial food. In fact, milk proteins help to maintain the balance of lean mass, osseous mass, and 
water, which accounts for $89.4 \mathrm{~g} / 100 \mathrm{~g}$ of hydric mass (Wu et al., 2016). Furthermore, its balanced macronutrient and micronutrient provides them with high biodisponibility. Moreover, milk has a protective effect on the cardiovascular system by lowering the risk of arterial hypertension, as well as a protective effect against metabolic syndrome, childhood obesity, type 2 diabetes, certain cancers, nervous system disorders, and immune or digestive system disorders (Thorning et al., 2016).

Since several years, milk has been the target of an anti-milk movement that denies all of its health benefits. It has been also accused of being linked to a variety of diseases, including hormone-dependent cancers (due to the presence of hormones in milk), cardiovascular disease and obesity (due to its high content of saturated fats and cholesterol (Siri-Tarino et al., 2010), chronic gastrointestinal inflammation (McNees et al., 2015) and even questioning its place in the diet. The activists behind this movement support their cause by pointing out that milk is directly linked to lactose intolerance, which has reached a global prevalence of $75 \%$, as well as allergies to milk proteins, which rank first among allergies in children and infants. On a national level, in addition to the health issues mentioned above, the availability of milk to consumers is extremely heterogeneous in some Tunisian regions. Several factors are involved, such as the rise in industrial milk prices, the lack of access to pasteurized milk, or other socioeconomic or demographic factors. On the other hand, milk has long been thought to be a carrier of microorganisms that cause a variety of infectious diseases. In fact, according to the study, milk is a vector of the Mycobacterium bovis, which causes extra-pulmonary tuberculosis, which is still prevalent in Tunisia.

Another major reason for which proponents of the movement argue is that the manufacturing of milk and dairy products is responsible for the emission of greenhouse gases with harmful effects on the environment. This production was estimated to be in the range of 1969 million tonnes of C02 equivalent (26\%) for global milk production in 2007 (about 553 million tonnes), which equates to $4 \%$ of total global greenhouse gas emissions. Reliant on his mother nature, and facing the alarming rates of diseases linked to milk consumption, man must develop animal-free alternatives to dairy products, such as the development of plant-based milks.

Vegetable milks are obtained by boiling and filtering plant matter (Sethi et al., 2016), which we may divide into five major categories: cereal-based lattes (oat, rice, etc.), legumes (soy, nut, etc.), nuts (almond, coco, hazelnut, pistachio, etc.), seeds (sesame, linen, hemp, etc.), and milks made from pseudo-cereal (quinoa, amaranth, etc.). Each form of milk has a different nutritional makeup depending on the first material used. Quinoa milk, for example, is known for its high levels of protein and polyunsaturated fatty acids of the omega 3 and omega 6 kinds. While hemp grain milk is high in monounsaturated fatty acids, almond milk is high in fibers, vitamins, and minerals (Silva et al., 2020), antioxidants and phytoestrogens. As a result, these gluten-free lattes would be a good option for those who have health issues related to milk and dairy products, as well as those who consume gluten-free products. When it comes to environmental effect, plant-based milks have a less impact than cow's milk. In fact, a study published in (Smedman et al., 2010) found that the CO2 emissions from animal-derived milk are in the range of $99 \mathrm{~g} \mathrm{CO} 2$ equivalent/100 $\mathrm{g}$ of product, compared to 30 and $21 \mathrm{~g}$ CO2 equivalent/100 $\mathrm{g}$ of product for soy and oat, respectively. The water footprint (the amount of water required for the manufacture of a product) is a second indicator that researchers use to estimate the impact of food on the environment. In this 
context, it was estimated that producing a litre of cow's milk necessitated 628 liters of water, compared to 371 liters for almond, 270 liters for rice, 48 liters for oat, and 28 liters for soy milk (Poore and Nemecek, 2018) .

In this context, our research has focused on plant-based milks as a nutritional, economic, and environmental alternative to cow's milk and dairy products. As a result, we attempted to the preparation of four plant-based milks: oat, almond, hemp, and quinoa's milk. The nutritional composition of each milk, as well as its physico-chemical characteristics, microbiologic stability, and antioxidant potential, were determined in order to investigate the effect of the first ingredient on the overall quality of the plant milk. Finally, a sensory analysis was conducted with a group of Tunisians in order to determine the acceptability of these products that are still unfamiliar to many.

\section{Material and Methods}

2.1. Plant sampling: During this research, we attempted to make four different types of plant milks: almond (made from nuts), oats (made from seeds), hemp (made from grains), and quinoa (made from pseudocereals). Seeds were purchased from Tunisan local market.

2.2. Milk preparation: The first step is to soak vegetable materials in tap water for 12 hours in a refrigerator set at 4 degrees Celsius. After that, 200 gr of each vegetable material were rinsed and mixed for 5 minutes in a mixer (Moulinex Power Blendy $400 \mathrm{~W}$ ) with mineral water in a 1:5 ratio. Finally, the vegetable milk were obtained by filtering the mixture through a vegetal milk bag. The obtained filtrate was kept in the refrigerator until analysis.

\subsection{Determination of the nutritional composition of vegetable milks}

Protein content: The kjeldhal technique was used to determine the total protein content of each milk sample. In summary, the first step is to demineralize the organic matter using sulfuric acid, followed by a second step of alkalinizing the reaction products. The coefficient of conversion of organic azote to proteins is 6.25 (Damasceno et al., 2020).

Lipid content: It was determined by dissolving milk in a solvent, which in this case is ether diethylique, and then evaporating the solvent (Damasceno et al., 2020).

Sugar content. The sugar content was determined using spectrophotometry (Damasceno et al., 2020).

Fiber content: The fiber content was determined using AOAC 2015 standards. A portion of $2 \mathrm{~g}$ lyophilized milk is placed in $200 \mathrm{ml}$ of $1,25 \mathrm{H} 2 \mathrm{SO} 4$ and boiled for 30 minutes. The solution was then placed in a funnel bucher with a muslin fabric. The residue was filtered and then washed with hot water to remove the acid. The residue was then placed in $200 \mathrm{ml}$ of $1.25 \% \mathrm{NaOH}$ and boiled for 30 minutes before being filtered. The residue is then placed in a humidity extraction oven until it reaches a constant weight.

Calcium content: The calcium content was determined using spectrophotometry (Damasceno et al., 2020).

\subsection{Determination of the antioxidant activity and the total polyphenol content}

Extraction: For the extraction step, a total of $25 \mathrm{~mL}$ of an $80 \%$ methanol solution was added to $5 \mathrm{~g}$ of each lyophilized sample, followed by agitation for 24 hours at room temperature. The tubes were then centrifuged for 5 minutes at $6000 \mathrm{tr} / \mathrm{min}$. The surnageant (extract) was collected after centrifugation for analysis (Yilmaz-Ersan et al., 2018). 
The capacity to neutralize the DPPH radical measurement: The anti-oxidant activity were assessed in vitro using the DPPH $^{\circ}$ method (BenJemaa et al., 2021). A sample of $1 \mathrm{ml}$ of each plant extract $(20$ $\mathrm{mg} / \mathrm{ml}$ ) is placed in the presence of $250 \mu \mathrm{l}$ of DPPH (0.22 $\mathrm{mM}$ in methanol). The mixture is placed in the dark for 30 minutes to react, and the absorbance is measured at $517 \mathrm{~nm}$ against a negative control. The results were expressed as a percentage of inhibition, which is calculated as the intensity of the coloring of the mixture decreases, according to the formula:

$$
\begin{gathered}
\mathrm{IC}=(\mathrm{DO} \text { control }-\mathrm{DO} \text { sample } / \mathrm{DO} \\
\text { control }) * 100
\end{gathered}
$$

IC: inhibition capacity; DO control: control absorbance; DO sample: the absorbance of investigated milk extract.

\subsection{Physico-chemical properties of} vegetal milk pH: The $\mathrm{pH}$ of the four milks was determined by diluting them 1:10 in pure water and measuring them using a $\mathrm{pH}$ meter. For each studied sample, all measurements were taken at ambient temperature (Aziz et al., 2018). The color was measured with a colorimeter, and the results were expressed in terms of the chromatic space $\mathrm{L} * \mathrm{a} * \mathrm{~b} *$ as defined by the International Commission on Lighting (CIE) in 1976. The three coordinates represent the color's clarity $\left(\mathrm{L}^{*}\right)$, its location between red and green $\left(\mathrm{a}^{*}\right)$, and its position between yellow and blue ( $b^{*}$ ) (Tapsell et al., 2006).

The whiteness index was calculated using the following formula:

$$
\left.W I=100-\sqrt{ }\left((100-L)^{2}+a^{2}+b^{2}\right)\right)
$$

2.6. Evaluation of the microbiologic stability of plant milks: The microbiologic stability of the studied milks was assessed by counting sample's living flore stored at $4^{\circ} \mathrm{C}$ for 12 days. To do so, $100 \mu$ l of each milk were pre-mixed at $\mathrm{j}=1 ; 4 ; 8 ; 12$ in order to do a series of dilutions $(1: 10)$ up to $10^{-3}$ (BenJemaa et al., 2017). $100 \mathrm{~mL}$ of each of the last two dilutions were plated on agar plates (Muller Hinton for Bacteria and Sabouraud for yeast and fungi) and viable colonies were counted after incubation for 24 hours at $37^{\circ} \mathrm{C}$ for Bacteria and 5 days at $20^{\circ} \mathrm{C}$ for yeast and fungi. The following formula (Ałtyn et al., 2020) was used to calculate the Colony Formant Unit (CFU):

$$
\mathrm{N}(\mathrm{CFU} / \mathrm{ml})=\frac{\sum \mathrm{c}}{\mathrm{V}(\mathrm{n} 1+\mathrm{n} 2 * 0,1) \mathrm{d}}
$$

$\sum \boldsymbol{c}=$ Total number of colonies counted in boxes with a number of colonies ranging from 20 to 300; V: inoculum volume in each bottle; $n 1$ : the number of Petri dishes counted in the first dilution; $\mathrm{n} 2$ : the number of Petri dishes counted in the second dilution; $\mathrm{d}$ : dilution factor, based on which the first counts were made.

\subsection{Sensory analysis of vegetal milks:} The sensory analysis took place over five hours at the University Mahmoud El Materi, with 70 students. The samples were kept at $15^{\circ} \mathrm{C}$ throughout the experiment and served in $20 \mathrm{ml}$ pots filled halfway. A hedonic test to determine the acceptability of products in terms of color, odor, taste, and aftertaste by panels (BenJemaa et al., 2021).

2.8. Statistical analysis: The data from the sensory analysis were treated with Excel 2007 program. The statistical analysis was carried out with the help of the statistical software SPPSS version 23, and a margin of error of $5 \%$ was taken into account. The number of participants considered for the hedonistic test is 60 .

\section{Results}

With a similar appearance and color to cow's milk but a different flavor, can plant-based milks have a nutritious composition and interesting physico-chemical properties to 
replace cow's milk in people with intolerances, allergies, or other health issues?

\subsection{Nutritional composition of} vegetable milks determination: In terms of carbohydrates, oat milk has the highest content $(23 \mathrm{~g} / 100 \mathrm{ml})$, compared to other vegetable milks ( $6 \mathrm{~g}$ for almond, $7 \mathrm{~g}$ for hemp, and $3.7 \mathrm{~g}$ for quinoa milk). The comparison of observed values with those of cow's milk reveals that, with the exception of quinoa's milk, the vegetal milks studied are richer in carbohydrates. In fact, the carbohydrate content of almond, oat, and hemp's milk is significantly higher than that of cow's milk (4.85g/100g).

In terms of protein content, the results showed that different tested milk varieties had different levels of content. In comparison to other plant-based milk ( $3 \mathrm{~g}$ for hemp, $2 \mathrm{~g}$ for almond, 1.5 for quinoa), oat milk has a higher content $(5 \mathrm{~g} / 100 \mathrm{ml})$. The protein content of hemp milk is comparable to that of cow's milk (3 g/100g), however the protein content of almond and quinoa milks is lower. It is worth noting that oat's milk is higher in protein than cow's milk. Hemp's milk has the highest lipid content ( $7 \mathrm{~g} / 100 \mathrm{~g}$ ) when compared to other vegetal milk $(2.7 \mathrm{~g} / 100 \mathrm{~g}$ for almond and oat's milk, and $1.8 \mathrm{~g} / 100 \mathrm{~g}$ for the quinoa's milk). This content is much higher than that of cow's milk (3.63g/100 g).

In terms of fibers, it is worth noting that almond, oat, and quinoa milks have high fiber content $(1 ; 3$; and $1.5 \mathrm{~g} / 100 \mathrm{~g}$, respectively). The focus on the calcium content of studied plant-based milks showed that the four samples have higher levels $(375 \mathrm{mg} / 100 \mathrm{~g}$ for hemp, $360 \mathrm{mg} / 100 \mathrm{~g}$ for oat, $341 \mathrm{mg} / 100 \mathrm{~g}$ for quinoa milk, and $225 \mathrm{mg} / 100 \mathrm{~g}$ for almond milk) than cow's milk (120 mg/100g).

Table 1. Nutritional comparison of the four tested vegetable milk and cow's milk.

\begin{tabular}{lccccc}
\hline $\begin{array}{l}\text { Milk's } \\
\text { type }\end{array}$ & $\begin{array}{c}\text { Carbohydrates } \\
(\mathbf{g} / \mathbf{1 0 0} \mathbf{g})\end{array}$ & $\begin{array}{c}\text { Proteins } \\
\mathbf{( g / 1 0 0 ~ g )}\end{array}$ & $\begin{array}{c}\text { Lipids } \\
\mathbf{( g / 1 0 0} \mathbf{g})\end{array}$ & $\begin{array}{c}\text { Fibers } \\
\mathbf{( g / 1 0 0} \mathbf{g})\end{array}$ & $\begin{array}{c}\text { Calcium } \\
(\mathbf{m g} / \mathbf{1 0 0} \mathbf{g})\end{array}$ \\
\hline Almond & $6 \pm 2.03 \mathbf{c}$ & $2 \pm 0.05 \mathbf{b}$ & $2.7 \pm 0.9 \mathbf{b}$ & $1 \pm 0.06 \mathbf{b}$ & $225 \pm 23 \mathbf{b}$ \\
Oat & $23 \pm 1.5 \mathbf{e}$ & $5 \pm 0.7 \mathbf{d}$ & $2.7 \pm 0.65 \mathbf{b}$ & $3 \pm 0.36 \mathbf{d}$ & $360 \pm 10 \mathbf{d}$ \\
Hemp & $7 \pm 0.6 \mathbf{d}$ & $3 \pm 1.2 \mathbf{c}$ & $7 \pm 1.41$ & $0 \pm 0.01 \mathbf{a}$ & $375 \pm 75 \mathbf{e}$ \\
Quinoa & $3.7 \pm 0.02 \mathbf{a}$ & $1.5 \pm 0.01 \mathbf{a}$ & $1.8 \pm 0.02 \mathbf{a}$ & $1.5 \pm 0.07 \mathbf{c}$ & $341 \pm 6 \mathbf{c}$ \\
Cow & $4.85 \pm 1.01 \mathbf{b}$ & $3.32 \pm 1.01 \mathbf{c}$ & $3.63 \pm 1.3 \mathbf{c}$ & $0 \pm 0.02 \mathbf{a}$ & $120 \pm 11 \mathbf{a}$ \\
\hline *T
\end{tabular}

\subsection{Physicochemical propreties of vegetable milks}

pH measurement: The acidity of the four plant-based milks studied is represented in Table 2. The results show that the $\mathrm{pH}$ values measured are statistically similar and close to neutrality.

Table 2. pH determination of almond, oat, hemp, and quinoa's milk.

\begin{tabular}{ccccc}
\hline & Almond & Oat & Hemp & Quinoa \\
\hline pH & $6,72 \pm 0.02 \mathbf{a}$ & $6,61 \pm 0.9 \mathbf{a}$ & $6,90 \pm 0.84 \mathbf{a}$ & $6,46 \pm 0.6 \mathbf{a}$ \\
\hline \multicolumn{7}{l}{ The values that are followed by the same letter are not statistically different at $\mathrm{p}<0.05}$.
\end{tabular}

Colorimetric proprieties of vegetable milks The colorimetric properties of almond, oat, hemp, and quinoa's milk were expressed as a function of the Whitening Index WI, which was calculated using the chromatic space $\mathrm{L}^{*}$ $\mathrm{a}^{*} \mathrm{~b} *$ of each milk. The data in Table 3 represent the obtained results.

Table 3. Colorimetric properties of plant milks expressed as a function of the chromatic space $\mathrm{L}$ ${ }^{*} \mathrm{a}^{*} \mathrm{~b}^{*}$ and the Whitening Index

\begin{tabular}{lcccc}
\hline & $\mathbf{L}^{*}$ & $\mathbf{a}^{*}$ & $\mathbf{b}^{*}$ & $\mathbf{W I}$ \\
\hline Almond & $21,54 \mathbf{c}$ & $0,43 \mathbf{d}$ & $3,32 \mathbf{b}$ & $21,46 \mathbf{c}$ \\
Oat & $9,56 \mathbf{b}$ & $-0,84 \mathbf{b}$ & $3,51 \mathbf{b}$ & $9,48 \mathbf{b}$ \\
Hemp & $34,99 \mathbf{d}$ & $-0,05 \mathbf{c}$ & $1,53 \mathbf{a}$ & $34,97 \mathbf{d}$ \\
Quinoa & $0,19 \mathbf{a}$ & $-1,25 \mathbf{a}$ & $3,98 \mathbf{b}$ & $0,10 \mathbf{a}$ \\
\hline
\end{tabular}

The values that are followed by the same letter are not statistically different at $\mathrm{p}<0.05$. 
It is worth noting that, despite their white hue, the four studied vegetal milks had distinct colorimetric properties. In fact, the calculation of each milk WI yielded statistically unique values. Furthermore, the highest WI was found in hemp's milk, which was in the range of 34.97 , followed by almond's milk (WI= 21.46), and then oat's milk (WI=9.48). Quinoa's milk, on the other hand, has the lowest WI (WI=0.1).
3.3. Total polyphenol measurement and antioxidant activity determination

Total polyphenol measurement: The quantitative assessments of the total phenol content were determined using the equation of linear regression of the calibration curve, which was traced using Gallic acid as a reference. The results are expressed in milligrams of EAG per milligram of DM (Figure 1).

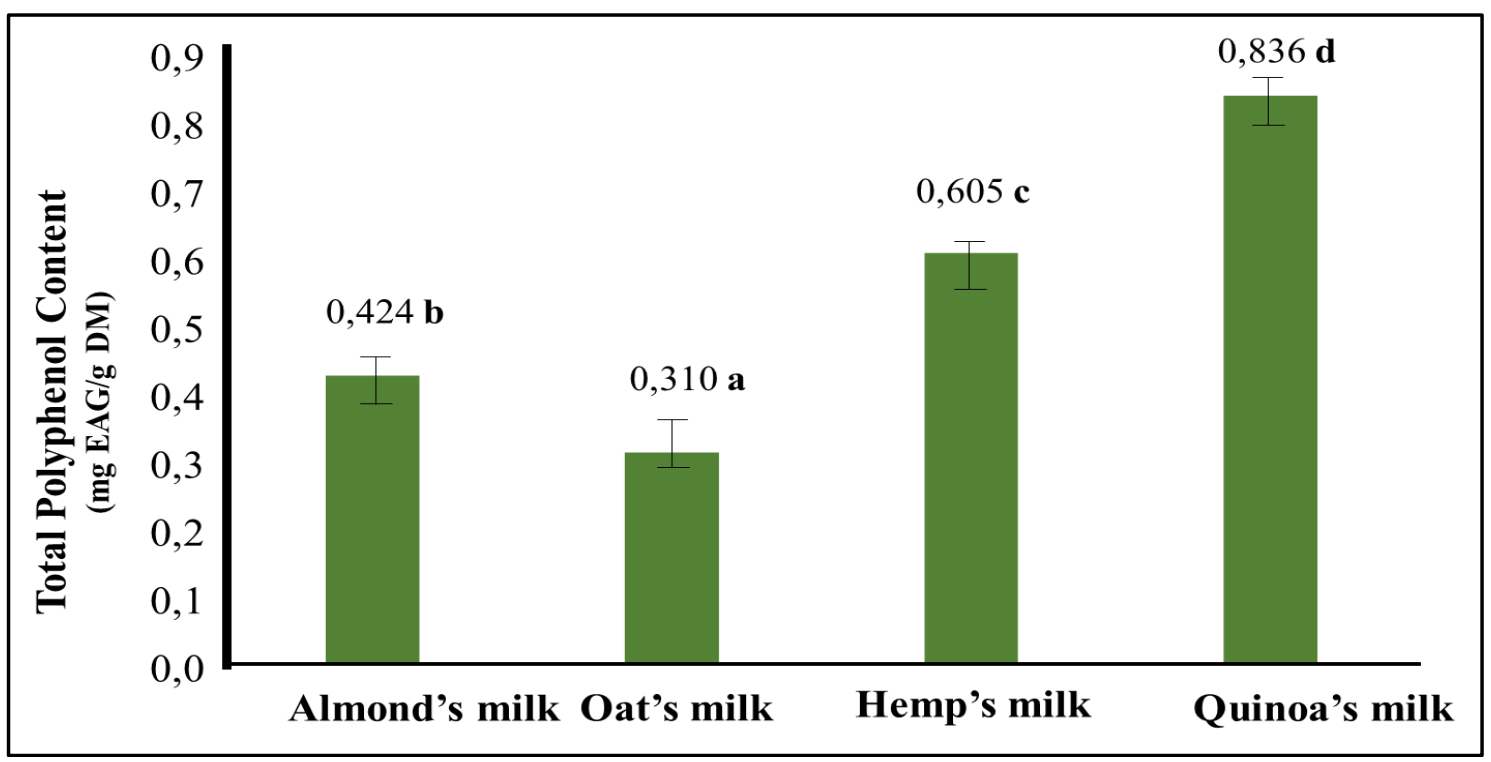

Figure 1. Total polyphenol content of almond, oat, hemp, and quinoa's milks at a concentration of $200 \mathrm{mg} / \mathrm{ml}$. The results are expressed in $\mathrm{mg}$ EAG/g DM. The values that are followed by the same letter are not statistically different at $\mathrm{p}<0.05$.

The findings showed that the four plantbased milks have an interesting total polyphenol content, with significant variation depending on the species. In fact, measured content ranged from $0.31 \mathrm{mg}$ EAG/g DM (oat milk) to $0.836 \mathrm{mg} \mathrm{EAG/g} \mathrm{DM}$ (quinoa milk).

The capacity to neutralize the DPPH radical measurement: The DPPH method is based on determining the amount of DPPH radical neutralised by an antioxidant, which is in this case a bioactive compound found in plant milk samples (Figure 2).

The findings showed that the studied plantbased milks have an antioxidant potential, as measured by their ability to absorb the free radical $\mathrm{DPPH}^{+}$. In this context, oat and hemp milks had similar capacities (PI $=63 \%$ ), however almond and quinoa milks had higher potential $(73.12$ et $78.34 \%$, respectively).

\subsection{Evaluation of the microbiologic} stability of plant milks: The microbiologic stability of the four studied plant-based milks was assessed by bacterial and fungal enumeration of milk samples stored at $4^{\circ} \mathrm{C}$ for 12 days. The obtained results are shown in Figures 3A and 3B.

The results of Figure $3 \mathrm{~A}$ showed that the bacterial contamination of hemp's milk developed quickly. In fact, after four days of storage at $4^{\circ} \mathrm{C}$, the number of the living 
bacteria in the hemp's milk had surpassed $200 * 10^{4} \mathrm{CFU} / \mathrm{ml}$. However, the rate of bacterial growth in almond and oat's milk was slower, and the enumeration did not reach $200 * 10^{4} \mathrm{CFU} / \mathrm{ml}$ until after 8 days of storage at $4^{\circ} \mathrm{C}$. It is worth noting that quinoa's milk had the best bacterial stability, with a maximum denomination of $56 * 10^{4} \mathrm{UFC} / \mathrm{ml}$ for the first 8 days of storage. Even though, a substantial increase in this charge $\left(300 * 10^{4}\right.$ $\mathrm{CFU} / \mathrm{ml}$ ) was seen towards the end of the study.

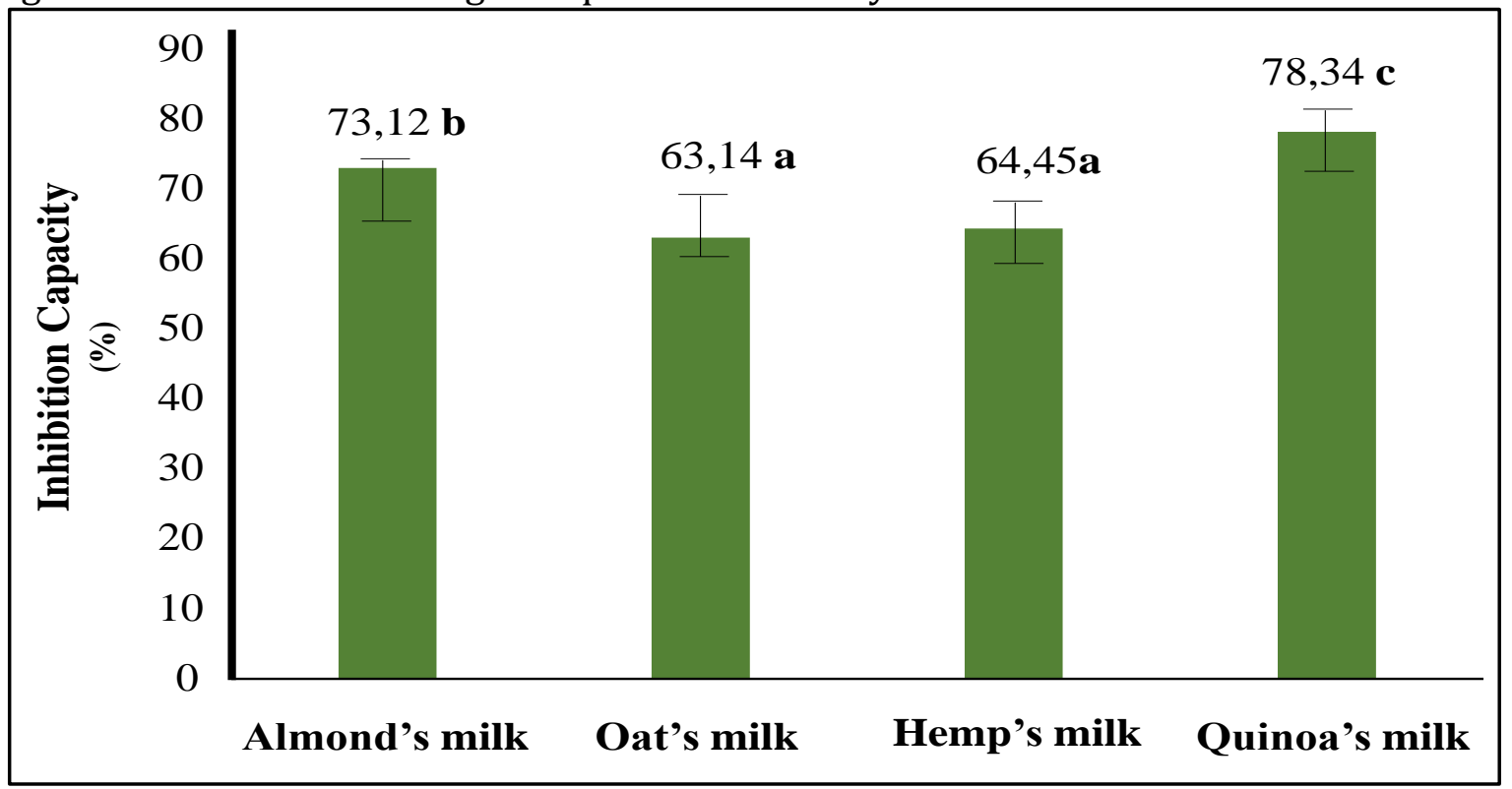

Figure 2. The radical DPPH inhibition capacity measurement of almond, oat, hemp and quinoa's milk $(20 \mathrm{mg} / \mathrm{ml})$. The results are expressed as a percentage of inhibition capacity. The values that are followed by the same letter are not statistically different at $\mathrm{p}<0.05$.

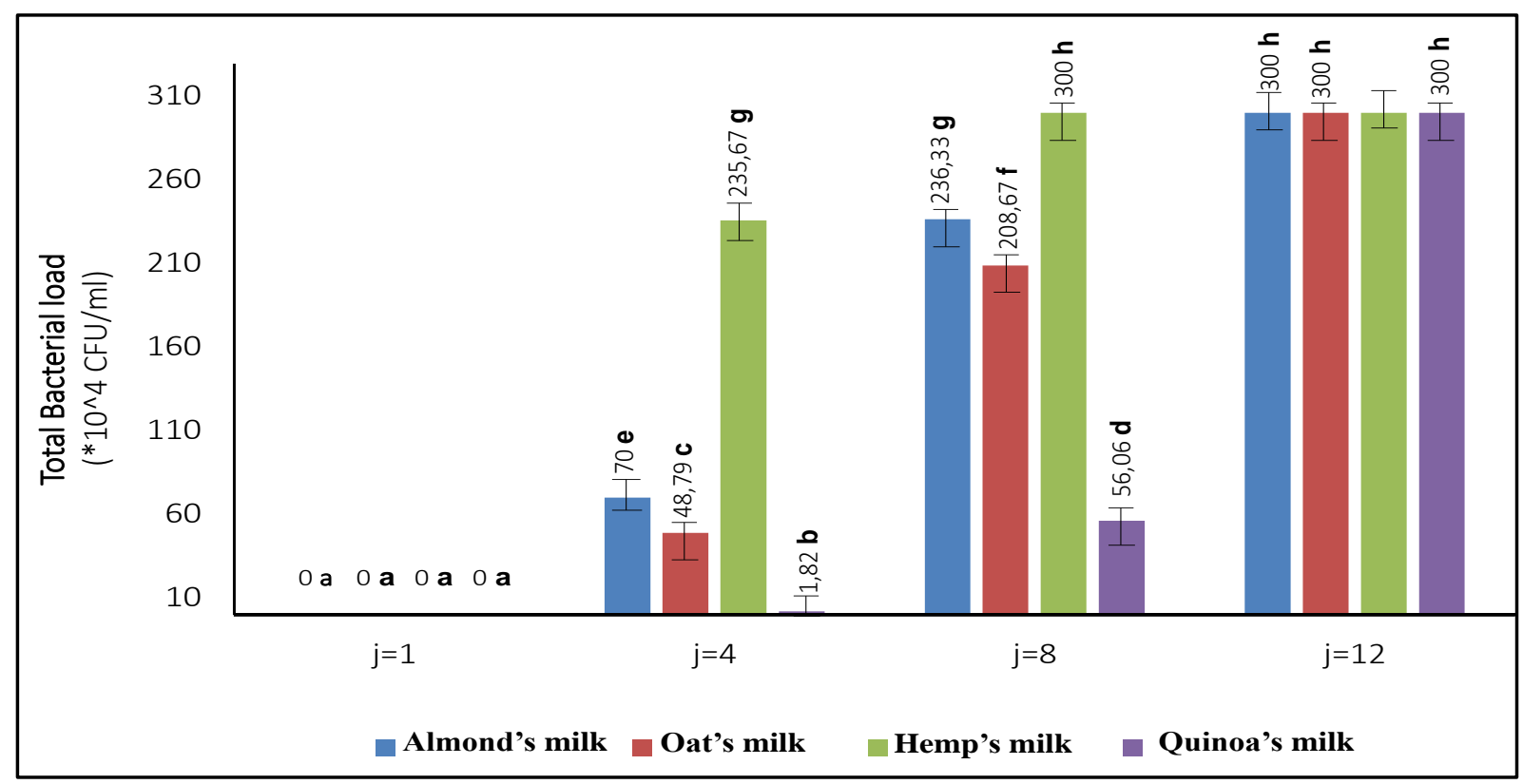

Figure 3A. Total bacterial load of almond, oat, hemp, and quinoa's milk, stored at $4^{\circ} \mathrm{C}$ for 12 days. The results are expressed in $* 10^{4} \mathrm{CFU} / \mathrm{ml}$. The values that are followed by the same letter are not statistically different at $\mathrm{p}<0.05$ 


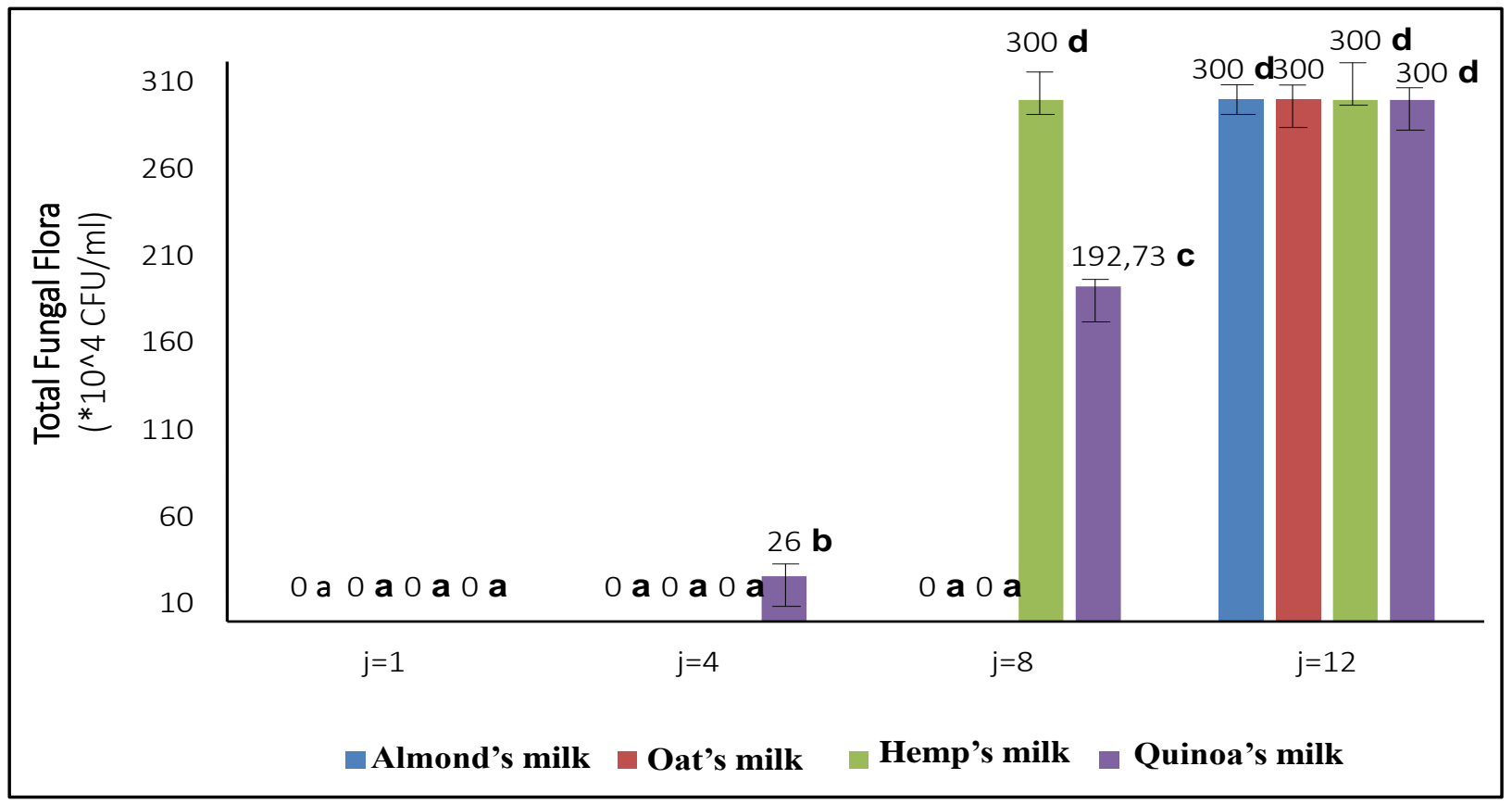

Figure 3B. Total fungal load of almond, oat, hemp, and quinoa's milk, stored at $4^{\circ} \mathrm{C}$ for 12 days. The results are expressed in $* 104 \mathrm{CFU} / \mathrm{ml}$. The values that are followed by the same letter are not statistically different at $\mathrm{p}<0.05$.

Figure 3B showed that the four studied vegetal milks were able to maintain their fungal stability for up to four days with charges less than $26 * 10^{4} \mathrm{CFU} / \mathrm{ml}$. However, at the end of the eighth day of storage at $4^{\circ} \mathrm{C}$, the charges in yeast and fungi of the hemp and quinoa's milks had rapidly developed and reached $200 * 10^{4} \mathrm{CFU} / \mathrm{ml}$. It is worth noting that almond and oat's milks had better fungal stability and were free of contaminants up to the eighth day of storage.

3.5. Sensorial hedonic analysis: The hedonic test of the four tested varieties (shown in Figure 4) showed that the evaluation of organoleptic attributes (color, odor, taste, after taste, and the overall appreciation) varies depending on the milk's type.

In terms of color, it is worth noting that almond's milk was the most appreciated, with a score of 3.76. On the other hand, oat's milk was the least liked, receiving a score of 3.02. For other milks, their overall ratings are 3.41 and 3.06 for quinoa and hemp's milk, respectively.

In terms of odor perception, the ratings assigned to the four milks were similar, ranging from 3 to 4 , with a score of 3.86 for quinoa's milk, 3.68 for hemp's milk, 3.45 for almond's milk, and 3.27 for oat's milk. It can be concluded that quinoa's milk has the best odor compared to oat's milk, which has the worst odor.

The almond's milk was the most well-liked sample, with a score of 3.86 , while the quinoa's milk was far less well-liked, with a score of 2.47. For the other varieties of vegetal milks, a score of 3.21 was given to oat's milk and a score of 2.62 was given to hemp's milk. 


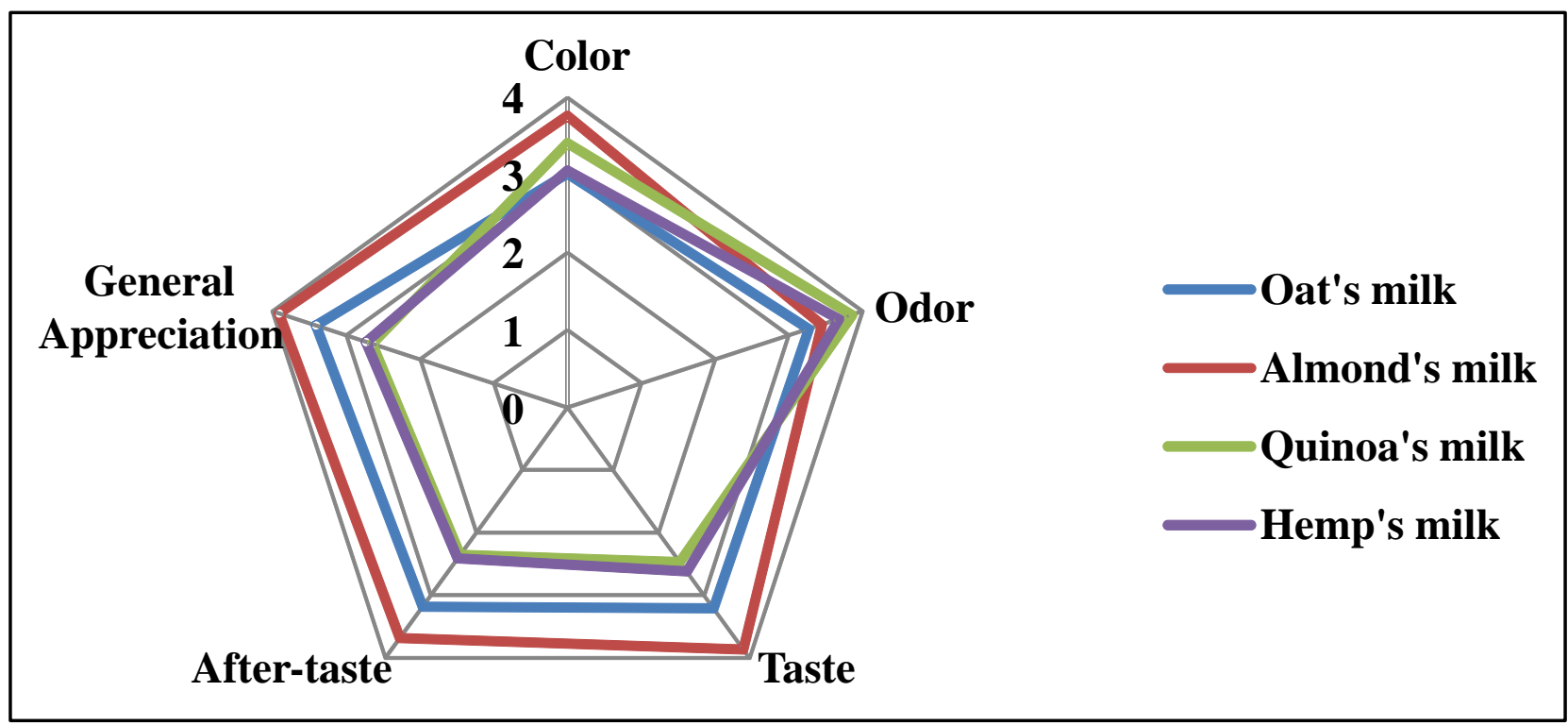

Figure 4. Hedonic sensory analysis of almond, oat, hemp, and quinoa's milk. The results are expressed on a five-point scale ( 1 being the least liked and 5 being the most liked). The values that are followed by the same letter are not statistically different at $\mathrm{p}<0.05$.

\section{Discussion}

Milk substitutes of plant origin, or plant extracts, are preparations extracted from legumes, oleaginous fruits, cereals or pseudocereals, and are known for their beneficial effects on human health. All plant-based beverages are defined as fluids resulting from the maceration, grinding, and filtering processes, which include extracting nutritional components from water (representing approximately $80 \%$ of the final product) (Munekata et al., 2020).

Their white color and somewhat thicker texture, similar to that of cow's milk, is the result of decomposition and the size reduction of the raw materials and their homogenization, earning them the mark "plant-based milk". Even if others argue that this word should not be used to describe these products and that we should instead refer to them as "milk substitutes," as suggested by the Codex Alimentarius Commission in 1994, which defines a "subtitution aliment" as "an aliment designed to resemble another aliment".
Although "plant-based milk" are commonly known as low-caloric and low-fat foods, but this is not valid for all types of milk.

We came to the conclusion that plant-based milks are not necessarily lower in calories than cow's milk (60 kcal $/ 100 \mathrm{~g}$ of product) (Vanga et al., 2018). Their nutritional profiles, on the other hand, are more interesting. Although they do not include cholesterol or saturated fats, such as goat milk, some of them do contain polyunsaturated fatty acids of the omega 3 and omega 6 types (Munekata et al., 2020).

The literature has revealed a more interesting aspect on the nutritional front: their richness in micronutrients and bioactive compounds contained in the primary material, and which are known for their health benefits. For example, almond's milk contain significant amounts of vitamins $\mathrm{E}$ and $\mathrm{C}$, known for their anti-oxidant properties (Sethi et al., 2016). Legumes are a good source of mono- and polyunsaturated fatty acids, minerals $\left(\mathrm{Fe}^{2+}, \mathrm{Zn}^{2+}, \mathrm{Mg}^{2+}\right)$, and phytoestrogens (isoflavones), which are known for their effects in the fight against osteoporosis, cardiovascular disease, 
gastrointestinal cancer, and menopause symptoms (Patisaul et al., 2010).

This research focused on determining the nutritional profiling of four different varieties of plant-based milks (almond, oat, hemp, and quinoa's milk). The selection of milks was made based on their nutritional profiles and the importance of their consumption across the world. In order to maximize the nutritional value of these plant-based beverages, we compared their compositions to a standard beverage and discovered that their macronutrient and micronutrient content is now far more interesting and significant than nutritionist recommendations.

In this study, differences have been detected in the nutritional compositions of tested milks, and other studies' milks, which may be explained, in part, by the differences in the nutritional content of the original used materials, as demonstrated by the study for almonds (Yada et al., 2011). Indeed, environmental factors such as cultivation region, cultivation methods, climate conditions that vary between harvest years and grain maturity, and interactions between these factors all influence the nutritional value of almonds. Furthermore, because almonds are natural products, variation in their composition might be expected even within a single cultivar. This research has highlighted the importance of genotype as a primary factor in determining nutritional content.

Furthermore, the manufacturing method for plant-based milks differs. Our research focused on artisanal vegetable milks due to a lack of commercially available products, whereas other studies focused on commercial plant-based milks, implying that conservation, enrichment, and improvement processes were carried out because these products present a significant challenge in achieving a similar appearance to the cow's milk to which the consumer is accustomed.
Calcium is the micronutrient whose presence in plant-based milks is the most concerning. While our research revealed some interesting calcium levels for various types of plant milk, it remains that it has a relatively low biodisponibility when compared to calcium found in cow's milk. This may explain why, while the majority of plant-based milk substitutes have calcium levels similar to cow's milk, their biodisponibility varies depending on the added source, the most common of which being calcium carbonate and tricalcium phosphate (Silva et al., 2020).

The stability of the final product, according to the study (Silva et al., 2020), depend on the size of the obtained particles after the maceration and the grindin as well as the filtering of raw material. The plant-based milk substitute is made up of colloidal systems made up of large dispersed particles such as solid primary materials, proteins, fat globules, and amidon granules that easily settle (Sethi et al., 2016). As a result, creating a stable finished product that can be stored for a long time without leaving a sand, granule, chalky gold taste in the mouth is difficult. The use of stabilizers such as hydrocolloids to reduce the size of solid particles has been proposed as a solution to the problem of stability (Mäkinen et al., 2016).

We concluded that plant-based milks may be supplemented with nutritional additives in order to bring their nutritional profile closer to that of cow's milk, therefore altering their nutritional composition. Plant-based beverages are typically subjected to an ultrahigh temperature (UHT) treatment before being packaged to ensure food quality and safety while in storage. However, conventional high-temperature processing might accelerate the degradation of sensitive components such as vitamins and minerals. This could justify the fact that the nutritional profile might be harmed throughout the manufacturing process (Mäkinen et al., 2016). Given that the ability of plant-based milk to reduce the DPPH radical is dependent 
on the amount of polyphenol it contains, the DPPH and total polyphenol content must be positively correlated. Interestingly, this statement was confirmed because the highest DPPH inhibition (78.34\%) corresponds to the highest polyphenol content $(0.167 \mathrm{mg}$ $\mathrm{EAG} / \mathrm{ml}$ ) and the lowest DPPH inhibition $(63.14 \%)$ corresponds to the lowest polyphenol totality.

The majority of the $\mathrm{pH}$ values found in this study are similar to those found in many literature-based comparison studies. If the $\mathrm{pH}$ of the milk differs from the one found in our study, it could be due to a difference in the $\mathrm{pH}$ of the water or the addition of other compounds that can change the $\mathrm{pH}$ of the milk. For instance, we noted that the quinoa milk in our study had a slightly lower $\mathrm{pH}$ (6.46) than the milk in the study of Jeske et al., 2018. Actually, the addition of enzymes: to the latter (to improve its emulsifying properties), may not be optimal due to quinoa proteins. Alpha amylase and protease both require an acidic $\mathrm{pH}$ to perform their proteolysis properly (Jakopović et al., 2019), which could explain the $\mathrm{pH}$ difference between different quinoa's milks.

In terms of DLC determination, we attempted to compare our results to microbiologic standards related to raw milk, which must be less than $40^{*} 10^{4} \mathrm{CFU} / \mathrm{ml}$, owing to a lack of scientific studies highlighting the microbiologic properties of raw milk. We have seen that plant-based milks are more conducive to microorganism development from the start, making them unfit for consumption, which highlights the value of a thermal treatment to extend their shelf life (Munekata et al., 2020). In the study (Paul et al., 2020), the almond and oat's milk had a lifespan of 170 days and 28 days, respectively, at $4 \mathrm{C}^{\circ}$, highlighting the necessity of thermal treatment.

However, even after thermal treatment, the duration of life of the hemp's milk was found to be 3 days, leading us to conclude that the methods used to extend the lifespan of the hemp's milk are ineffective. Alternative treatment technologies such as high hydrostatic pressure, high-pressure homogenization, ultra-sons, and pulsing electrical fields have been proposed to reduce these drawbacks (Sethi et al., 2016). Other methods, such as the use of microwaves, high pressure, ultraviolet sterilization, pulsing electric fields, and ultrasons, can be used as alternatives to thermal treatments. A scientific evaluation of these novel treatment technologies revealed promising results in terms of extending the shelf life, preserving nutritional properties, and reducing the loss of bioactive compounds in plant-based foods (Silva et al., 2020).

There are few studies on the comparison of sensory analysis of plant milks in the literature. Nonetheless, the study (Jeske et al., 2018), the most similar to ours, compared the sensory properties of a variety of plant-based milks, including almond, oat, rice, soy, hemp, and lentils. Consumers ranked appearance, aroma, flavor, mouthfeel, and overall sensation as the most important sensory properties. The variability of the vegetable milk hedonic appreciation could be related to the industrial process used to improve one or more aspects of the plant milk. All of these processes have an effect on the organoleptic qualities of plant milks.

\section{Conclusion}

As a result of this research on plant-based milks, it could be concluded that these products have an interesting nutritional composition and physico-chemical properties, and that they could partially replace milk and milk products. Furthermore, these plant extracts include anti-oxidant properties that are known to be beneficial to health. These products, which do not have a place on the market with a local production, should attract the attention of industrialists in order to find a position among the other 
imported products, and why not among the dairy products.

\section{Author Contribution}

M.B.J., R.G., H.F., R.K. and R.S.B. contributed equally to the design and implementation of the research, to the analysis of the results and to the writing of the manuscript.

\section{Acknowledgements}

The Tunisian Ministry of Higher Education, Scientific Research, Information and Communication Technologies supported this study.

\section{Conflict of Interest}

The authors declare no conflict of interest.

\section{References}

1. Ałtyn, I., and Twarużek, M., 2020. Mycotoxin Contamination Concerns of Herbs and Medicinal Plants. Toxins. 12(3). doi: $10.3390 /$ toxins12030182.

2. Aziz, M.A., Khan, A.H., Adnan, M., and Ullah, H., 2018. Traditional uses of medicinal plants used by Indigenous communities for veterinary practices at Bajaur Agency, Pakistan. J Ethnobiol Ethnomedicine. 14(1):11. doi: 10.1186/s13002018-0212-0.

3. BenJemaa, M., Falleh, H., Neves, M.A., Isoda, H., Nakajima, M., and Ksouri, R., 2017. Quality preservation of deliberately contaminated milk using thyme free and nanoemulsified essential oils. Food Chemistry. 217: 726-734. doi: 10.1016/j.foodchem.2016.09.030.

4. BenJemaa, M., Hafsi, C., Falleh, H., Serairi Beji, R., and Ksouri, R., 2021. Essential Oils As Food Preservative: Encapsulation, Biological Activities, And Sensory Impact. In: The Seventh International Mediterranean Symposium on Medicinal and Aromatic Plants. ISBN: 978-605-61261-9-2.

5. Damasceno, L.R.A.D., Botelho, R.B.A., Rodrigues de Alencar, E., 2020. Development of novel plantbased milk based on chickpea and coconut. LWT. Food Science and Technology. 128, 109479. doi:10.1016/j.lwt.2020.109479.

6. Dewanto, V., Wu, X., and Liu, R.H., 2002. Thermal Processing Enhances the Nutritional Value of Tomatoes by Increasing Total Antioxidant Activity. Journal of agriculture and food chemistry. 14,50(17):4959-64. doi:10.1021/jf0115589

7. Jeske, S., Zannini, E., and Arendt, E.K., 2017. Evaluation of Physicochemical and Glycaemic Properties of Commercial Plant-Based Milk
Substitutes. Plant Foods for Human Nutrition. 72(1):26-33. doi: 10.1007/s11130-016-0583-0.

8. Mäkinen, O.E., Wanhalinna, V., Zannini, E., and Arendt, E.K., 2016. Foods for Special Dietary Needs: Non-dairy Plant-based Milk Substitutes and Fermented Dairy-type Products. Critical Reviews in Food Science and Nutrition. 56(3):339-49. doi: 10.1080/10408398.2012.761950.

9. McNees, A.L., Markesich, D., Zayyani, N.R., and Graham, D.Y., 2015. Mycobacterium paratuberculosis as a cause of Crohn's disease. Expert Review of Gastroenterology \& Hepatology. 9(12):1523-34.

doi: 10.1586/17474124.2015.1093931.

10. Munekata, P.E.S., Domínguez, R., Budaraju, S., Roselló-Soto, E., Barba. F.J., and Mallikarjunan, K., 2020. Effect of Innovative Food Processing Technologies on the Physicochemical and Nutritional Properties and Quality of Non-Dairy Plant-Based Beverages. Foods Basel Switz. 9(3). doi: 10.3390/foods9030288.

11. Paul, A.A., Kumar, S., Kumar, V., and Sharma, R., 2020. Milk Analog: Plant based alternatives to conventional milk, production, potential and health concerns. Critical Reviews in Food Science and Nutrition. $60 \quad(18): 3005-23 . \quad$ doi: 10.1080/10408398.2019.1674243.

12. Sethi, S., Tyagi, S.K., and Anurag, R.K., 2016. Plantbased milk alternatives an emerging segment of functional beverages: a review. Journal of Food Science and Technology. 53(9):3408-23. doi: 10.1007/s13197-016-2328-3.

13.Silva, A.R.A., Silva, M.M.N., and Ribeiro, B.D., 2020. Health issues and technological aspects of plantbased alternative milk. Food Research International. 131:108972. doi:10.1016/j.foodres.2019.108972

14. Siri-Tarino, P.W., Sun, Q., Hu, F.B., and Krauss, R.M., 2010. Saturated fat, carbohydrate, and cardiovascular disease. American Journal of Clinical Nutrition. 91(3):502-9. doi: 10.3945/ajcn.2008.26285.

15. Smedman, A., Lindmark-Månsson, H., Drewnowski, A., and Edman, A-K.M., 2010. Nutrient density of beverages in relation to climate impact. Food and Nutrition $\quad$ Research. $54 . \quad$ doi: 10.3402/fnr.v54i0.5170.

16. Tapsell, L.C., Hemphill, I., Cobiac, L., Patch, C.S., Sullivan, D.R., and Fenech, M., 2006. Health benefits of herbs and spices: the past, the present, the future. The Medical Journal of Australia. 185(S4):S1-24. doi: 10.5694/j.13265377.2006.tb00548.x.

17. Thorning, T.K., Raben, A., Tholstrup, T., SoedamahMuthu, S.S., Givens, I., and Astrup, A., 2016. Milk and dairy products: good or bad for human health? An assessment of the totality of scientific evidence. Food and Nutrition Research. 60:32527. doi: 10.3402/fnr.v60.32527. 
18.Vanga, S.K., and Raghavan, V., 2018. How well do plant based alternatives fare nutritionally compared to cow's milk? Journal of Food Science and Technology. 55(1):10-20. doi: 10.1007/s13197-017-2915-y.

19.Wu, G., 2016. Dietary protein intake and human health. Food and Function. 7(3):1251-65. doi: 10.1039/c5fo01530h.

20.Yada, S., Lapsley, K., and Huang, G., 2011. A review of composition studies of cultivated almonds: Macronutrients and micronutrients. Journal of Food Composition Analysis. 24(4):469-80. doi: 10.1016/j.jfca.2011.01.007.

21.Yilmaz-Ersan, L., Ozcan, T., Akpinar-Bayizit, A., and Sahin, S., 2018. Comparison of antioxidant capacity of cow and ewe milk kefirs. Journal of Dairy Sciences. 101:3788-3798. doi.org/10.3168/jds.2017-13871. 